\title{
Ecological impacts of LEBAME (efficient microorganism) in animal production
}

\begin{abstract}
Summary
The present work summarizes the results of the application of LEBAME in animal production. The LEBAME is a bioproducto developed by the Cuban Research Institute on Sugar Cane Derivatives (ICIDCA), which is made up of efficient microorganisms, belonging to the ICIDCA collection of microbiological cultures. This bioproducto was applied in the poultry industry in the treatment of fattening chickens beds and laying hens, with improvements in the environmental conditions of poultry facilities, reflected in an economic, social and environmental benefit. In The Swine Industry it was applied to study the impact in bio-digesters for the Biogas production. In this regard the results show that the inoculation of LEBAME in digesters accelerates the digestion of organic matter and, consequently, reduces the demand biological oxygen (DBO), efficiently reduces harmful gases, increasing the efficiency in digesters. Also decreases odors and the presence of flies and insects in the facilities.
\end{abstract}

Keywords: LEBAME, efficient microorganisms, animal production, environment
Volume 4 Issue 3 - 2019

\author{
Caridad Suarez Machin \\ Cuban Research Institute on Sugar Cane Derivatives (ICIDCA), \\ Cuba \\ Correspondence: Caridad Suarez Machin, Cuban Research \\ Institute on Sugar Cane Derivatives (ICIDCA) Avenue White \\ 804, Corner, Central Road, San Miguel del Padron, Havana, Cuba, \\ I 1000, Fax 7-6988243, Email caridad.suarez@icidca.azcuba.cu
}

Received: February 25, 2019 | Published: May 17, 2019

\section{Introduction}

The interest for an ecological agricultural production has increased considerably in the last years. Numerous studies, publications and products certify this.

The poultry and pork industry are important sources to meet the demand for protein of animal origin in the diet, using expensive facilities and sophisticated equipment that raise production costs, this coupled with the proper management of waste to generate a source of income and an adequate management of the environment in the farms, creates the need to carry out work that allows poultry producers to find economic alternatives for the efficient use and management of the pollinaza. ${ }^{1}$

Often, poultry and swine production residues are used as fertilizer and applied directly to the soil, without prior treatment. However, these practices can lead to serious contamination problems, because they produce large amounts of polluting substances (nitrogen, phosphorus and sulfur), ${ }^{2,3}$ as well as a pathogenic effect with the possible incorporation of microorganisms such as Salmonella sp. ${ }^{4}$

Bitzer and $\mathrm{Sims}^{5}$ reported that the excessive application of waste in agricultural systems can cause pollution in groundwater by nitrates that can cause risks to human and animal health.

Some of the alternatives for the treatment of poultry residues, environmentally accepted, are the anaerobic digestion, the production of Biogas, the composting and the treatment with efficient microorganisms. ${ }^{6,7}$

To establish an efficient and ecologically sustainable production system, is essential the use of technologies that increase energy efficiency.

The way to use waste industrially has been the development of technologies for the biogas production, which is the main product of anaerobic digestion, a biological degradation process in which part of the organic materials of a substrate are converted into a mixture of $\mathrm{CO}_{2}$, hydrogen, methane, hydrogen sulfide and traces of other elements.
At present, the use of biogas has diversified in the generation of electricity. It satisfies the local energy demands and also allows the incorporation of electric power to the national grid, projecting an increase of 45 biogas plants which will be distributed throughout the country before the year 2022, with a generation potential from $16.4 \mathrm{Gw} /$ year at the national energy system.

The introduction of efficient microorganisms in agricultural practice is one of the main contributions of microbiological research in recent decades.

The effective microorganisms (EM-1) are a mixed culture of natural beneficial microorganisms, without genetic manipulation, present in natural ecosystems, physiologically compatible between them, they are generally formed by a mixture of phototrophs bacteria, lactic acid and yeast and are a viable and sustainable option for agricultural and animal production within the organic and biological parameters, so as not to affect the environment, as well as to achieve high quality products with low cost. ${ }^{8}$

The use of efficient microorganisms in animal production is aimed at increasing the production variables and the management of excreta in the facilities to reduce the harmful action of microorganisms that cause putrefaction and bad odors (ammonia).

With its use is possible the elimination of bad odors and populations of insect pests (flies), which proliferate as a consequence of the process of fermentation of excreta in situ, are also used to improve the quality of the poultry litter, which in turn constitutes a food of high protein content, which can be used in the feeding of ruminants, and reduce the environmental impact caused by this type of farm.

With the use of efficient microorganisms (EM) it is possible to reduce the consumption of washing water, implementing the management of dry beds for the collection of excrement, reducing the frequency of water use in the maintenance of the facilities, decreasing oxidation and training of oxide, helping to extend the useful life of the facilities, from the economic point of view, with the use of EM reduces the requirement and use of disinfectants, which leads to the reduction of production costs. ${ }^{9}$ 
The LEBAME is a bioproducto developed by the Cuban Research Institute on Sugar Cane Derivatives (ICIDCA) which is made up of three microorganisms from its crop collection: Bacillus subtilis $\mathrm{B} / 23-$ 45-10 born, Lactobacillus bulgaricum B/103-4-1 and Saccharomyces cerevisiae L-25-7-12. These microorganisms are considered within the group of regenerators, which are able to protect the balance and health of the natural environment by stopping, directly or indirectly, the process of decomposition and putrefaction in all substances and generating bioactive substances.

This product was validated in different sectors of agriculture inside and outside of our country, obtaining positive and encouraging results. This work summarizes the main results obtained in the agricultural sector, framed towards the environmental benefit offered by the application of LEBAME in the animal production.

\section{Materials and methods}

\section{In fattening chickens}

The work was carried out in experimental farm 1 of the Poultry Research Institute, located at Km 231/2. Road "the Ceiba", Bejucal. Two experiments were carried out, during a period of four weeks each, in chickens of 14 to 42 days of age.
In the first experiment 25 paddocks were used and in the second 28 , each of $8 \mathrm{~m}^{2}$. The animals were distributed in a randomized trial of controlled type with 5 treatments and 5 repetitions each. The reproduction density was 10 chicks per square meter of floor (85 chickens per pen) for a total of 2380 chicks. The applied doses of LEBAME in each of the experiments are presented below in the following Table 1:

The product was applied, on the bed, in experiment 1 with a washing bottle and in experiment 2; it was sprayed with a backpack, always in the morning (9.00-10.00am) once a week.

The bed was sampled weekly, always before applying the LEBAME, taking samples in 5 points of each corral, thus forming the subsamples for each treatment, analyzing the behavior of the gravimetric dry matter (GDM), the $\mathrm{pH}$, total nitrogen in dry base (TN) and crude protein in dry base $(\mathrm{CP})$.

The data were processed in the statistical package STATGRAPHIC CENTURION XV. (1982-2007), are performing multifactorial ANOVA, where the main effects were treatments and weeks. The multiple range tests were applied by less significant difference (LSD) method to determine the statistical differences between the treatments and between the weeks of application.

Table I Dose applied by experiments

\begin{tabular}{llllll}
\hline Experiments & TI & T2 & T3 & T4 & T5 \\
\hline One & Control & $6.25 \mathrm{~mL} / \mathrm{m}^{2}$ & $9.38 \mathrm{~mL} / \mathrm{m}^{2}$ & $12.5 \mathrm{~mL} / \mathrm{m}^{2}$ & $18.75 \mathrm{~mL} / \mathrm{m}^{2}$ \\
One & & $20 \mathrm{~mL} / \mathrm{m}^{2}$ & $15 \mathrm{~mL} / \mathrm{m}^{2}$ & $10 \mathrm{~mL} / \mathrm{m}^{2}$ & $5 \mathrm{~mL} / \mathrm{m}^{2}$ \\
\hline
\end{tabular}

The poultry were reared according to the UECAN technical instructions and the current preventive medicine plan for this category of poultry.

All the groups had access to the same diet and the ration of these animals was unified ad libitum following the methodology of the critical route proposed by the Technical Instructions (2003). ${ }^{10}$

\section{In laying hens}

The study was carried out on shelter 9 of the Tejeda experimental farm of the Poultry Research Institute, located at Km 231르, Road "The Ceiba", Bejucal.

The hen manure, was composed by the excrement of foods, feathers, husks and other residues of eggs, derived from the lodging of Light reproducers of the $\tilde{\mathrm{N}}$; X1; NH and CO lines.

The LEBAME was sprayed, with a backpack, Model SH -12/16/20 Treatment 1, was the control, in which live lime was applied daily and the dose of treatments 2 and 3 was $250 \mathrm{~mL} / \mathrm{m}^{2}$, but with different application frequencies, 3 times a week in treatment number 2 and daily, for the 3 treatment.

Weekly, samples were taken in five points of each pit, forming a sample for each treatment, analyzing $\mathrm{pH}$, gravimetric dry matter (GDM), crude protein (CP) and total nitrogen (TN). The data was processed in the Stagraphics Centurion XV. (1982-2007), were performing multifactorial ANOVA, where the main factors were the weeks and treatments (frequency of application of LEBAME and application of quicklime). The multiple range comparison method used was by the LSD method. The poultry were bred according to the
UECAN technical instructions and the current preventive medicine plan for this category.

\section{In the swine industry}

The experiment was carried out in the Swine Research Institute, by the Department of the Environment. The LEBAME was inoculated directly into the tubular bio-digesters at different concentrations and methane measurements were made. The environmental conditions were submitted to a panel of sensory tests, using a group of judges with evaluation criteria.

\section{Results and discussion}

\section{In fattening chickens}

Below is the table that summarizes the multifactorial ANOVA performed in both experiments, reflecting the behavior of the variables studied, with respect to each factor (Table 2).

The table shows similarity between the results obtained in each experiment. There were highly significant differences $(p \leq 0.01)$ in the weeks of application, for all the variables studied, but not in terms of treatments (dose), in both experiments.

The main variables observed in both experiments that have a direct influence on environmental conditions will be shown below.

\section{$\mathrm{PH}$ analysis}

The Figure 1 and Figure 2 show the behavior of the $\mathrm{pH}$ in both experiments with respect to the doses and the weeks of application respectively. 


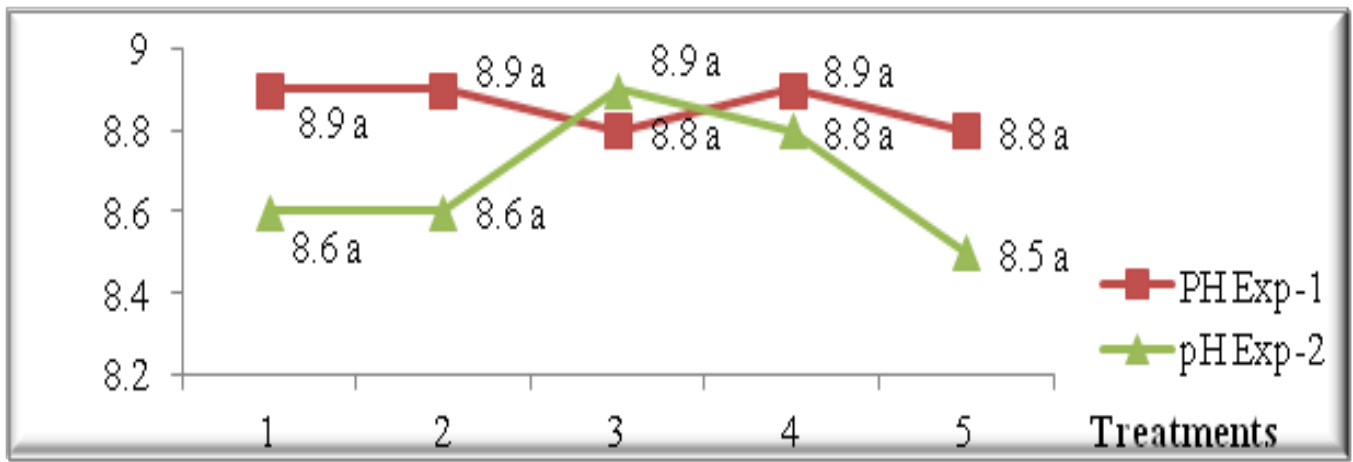

Figure I pH behavior according to doses applied.

*Values with uncommon letters differ from each other by LSD top $\leq 0.05$.

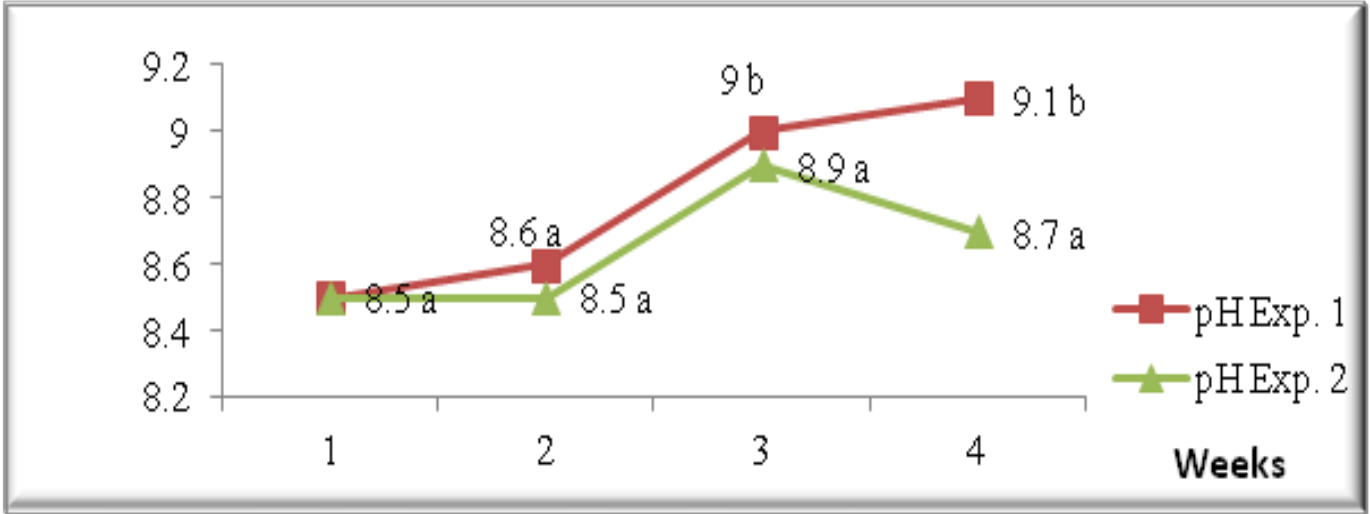

Figure $2 \mathrm{pH}$ behaviors over time.

*Values with uncommon letters differ from each other by LSD top $\leq 0.05$.

Table 2 Analysis of $\mathrm{pH}, \mathrm{GDM}, \mathrm{TN}$ and $\mathrm{CP}$ by treatments and weeks

\begin{tabular}{|c|c|c|c|c|c|c|c|c|c|c|}
\hline \multirow[b]{2}{*}{ Factors } & \multicolumn{2}{|l|}{ SC } & \multicolumn{2}{|l|}{ DF } & \multicolumn{2}{|l|}{ HS } & \multicolumn{2}{|c|}{ P-Value } & \multicolumn{2}{|c|}{ Sign. } \\
\hline & $\begin{array}{l}\text { Exp. } \\
\text { one }\end{array}$ & $\begin{array}{l}\text { Exp. } \\
\text { two }\end{array}$ & $\begin{array}{l}\text { Exp. } \\
\text { one }\end{array}$ & $\begin{array}{l}\text { Exp. } \\
\text { two }\end{array}$ & $\begin{array}{l}\text { Exp. } \\
\text { one }\end{array}$ & $\begin{array}{l}\text { Exp. } \\
\text { two }\end{array}$ & $\begin{array}{l}\text { Exp. } \\
\text { one }\end{array}$ & $\begin{array}{l}\text { Exp. } \\
\text { two }\end{array}$ & $\begin{array}{l}\text { Exp. } \\
\text { one }\end{array}$ & $\begin{array}{l}\text { Exp. } \\
\text { two }\end{array}$ \\
\hline \multicolumn{11}{|l|}{$\mathrm{pH}$} \\
\hline Treatment & 1.34 & 0.37 & 4 & 4 & 0.33 & 0.09 & 0.8 & 0.5 & NS & NS \\
\hline Week & 0.05 & 0.57 & 4 & 3 & 0.01 & 0.19 & 0.001 & 0.2 & *** & \\
\hline \multicolumn{11}{|l|}{ GDM } \\
\hline Treatment & 58.9 & 13 & 4 & 4 & 14.7 & 3.25 & 0.1 & 0.4 & NS & NS \\
\hline Week & 133.6 & 477.8 & & 3 & 33.4 & 159.2 & 0.001 & 0.001 & $* * *$ & $* * *$ \\
\hline \multicolumn{11}{|l|}{ TN } \\
\hline Treatment & 1.11 & $0.5 \mathrm{I}$ & & 4 & 0.28 & 0.12 & 0.5 & 0.08 & NS & NS \\
\hline Week & 51.4 & 13.7 & 4 & 3 & 12.9 & 4.58 & 0.001 & 0.001 & $* * *$ & $* * *$ \\
\hline \multicolumn{11}{|l|}{ CP } \\
\hline Treatment & 7.47 & 3.6 & 4 & 4 & 1.86 & 0.89 & 0.5 & 0.08 & NS & NS \\
\hline Week & 352.9 & 95.2 & & 3 & 88.2 & 31.7 & 0.001 & 0.001 & $* * *$ & $* * *$ \\
\hline
\end{tabular}


Figure 1 shows that there were no statistically significant differences between the different doses applied in each treatment of the experiments performed.

Figure 2 shows a statistically significant difference in experiment 1 between weeks 1 and 2 with respect to weeks 3 and 4, remaining in an alkaline range in all cases, increasing its value as the study time increased. The initial $\mathrm{pH}$ of the bed (8.5) does not coincide with what was proposed by Ferrer, ${ }^{11}$ who stated that the initial $\mathrm{pH}$ of digestible materials, garbage, manure, varies generally from 5.5 to 7.0, although in experiment 2 a better $\mathrm{pH}$ behavior, because although it slightly increases its value, it does not show significant differences between the weeks of study, remaining at acceptable levels for the control of the release of ammonia into the medium, so if we maintain the $\mathrm{pH}$ in ranges of 8.5 it is possible to reduce the emission of ammonia gases and improve the environmental conditions, which influences the accommodation of the poultry and, consequently, improves their productive and health expression.
Moore et al..$^{12}$ stated that ammonia is a cause of diseases for workers and animals of poultry farms and often for nearby communities and states that the increase in $\mathrm{pH}$ is due to the loss of organic acids through volatilization, microbial decomposition and release of ammonia through the mineralization of organic nitrogen.

\section{Analysis of total nitrogen}

In the following Figure 3 the similarity between the results obtained in each experiment is explained when analyzing the percentage of total nitrogen in the study time.

The graph shows the increase in the percent of total nitrogen in dry basis, as the period under study increases, coinciding with what was raised by Uribe ${ }^{13}$ who registered a considerable increase in nitrogen content in beds treated with MS. Moore et al. ${ }^{12}$ and Alvarez et al. ${ }^{14}$ found that nitrogen volatilization of poultry residues increases when $\mathrm{pH}$ values exceed 7, which could explain part of the nitrogen losses, through volatilization as ammonia.

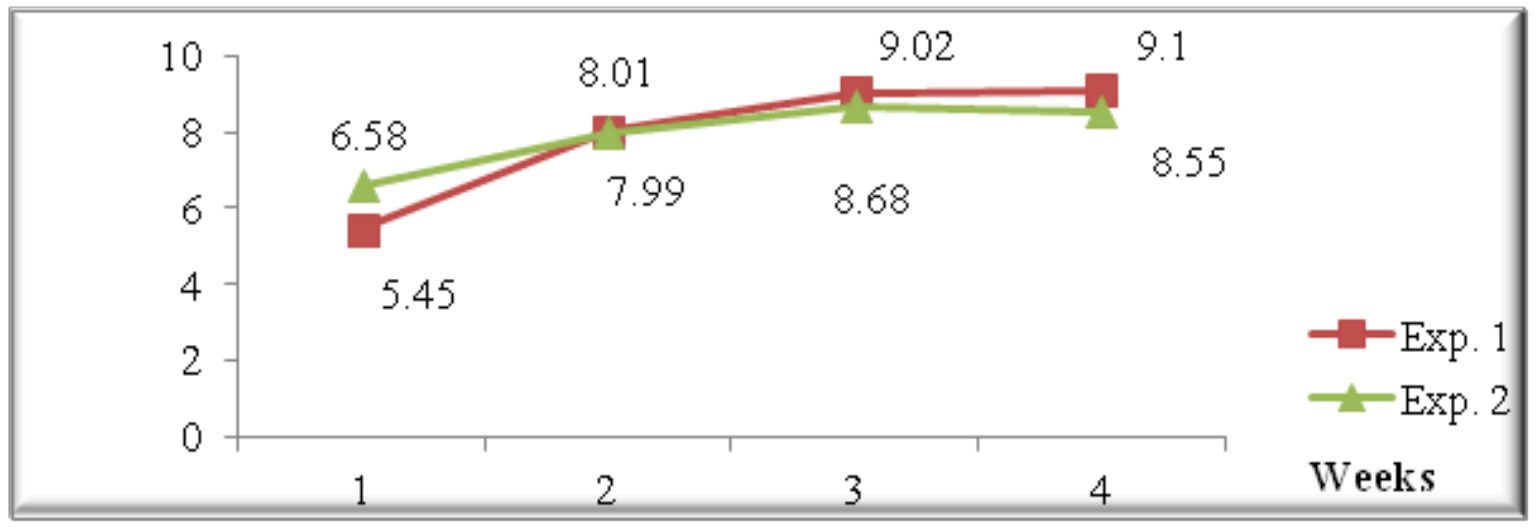

Figure $3 \mathrm{TN}$ behaviors in time for each experiment.

*Values with uncommon letters differ from each other by LSD top $\leq 0.05$.

The results obtained indicate an increase in nitrogen values that favors obtaining an excellent fertilizer and soil improver, because according to Rostagno et al. ${ }^{15}$ Poultry residuals, specifically poultry litter, are superior with respect to commercial fertilizers, because they provide important amounts of nitrogen, phosphorus, potassium and Organic matter, promote the slow release of nutrients to the soil, improve soil structure, as well as the water and nutrient retention capacity.

\section{Qualitative aspects}

In the interior of the shelter a considerable reduction of populations of plague insects was appreciated, as well as elimination of bad odors, improving the quality of the environment inside the shelter, coinciding with Brown ${ }^{16}$ who affirms that the elimination is possible of odors through microbial control with the use of microorganisms producing fermentation.

Therefore this by-product generated daily in poultry farms should be regarded as a product with high added value in order to economically favor production and enter a globalized market that demands products that improve the environment, of great acceptance in the commercial field and guarantee safe and efficient systems in poultry production.

The physical condition of the beds was qualitatively superior in the corral where the LEBAME was applied.

\section{In laying hens}

Table 3 summarizes the results of the multifactorial ANOVA to the variables studied.

Table 3 Summary of the $\mathrm{pH}, \mathrm{GDM}, \mathrm{TN}$ and CP analysis by factors

\begin{tabular}{llllll}
\hline $\mathbf{p H}$ & & & & & \\
\hline Factors & SC & DF & HS & P-Value & Sign. \\
Treatment & 0.09 & 2 & 0.05 & 0.7 & NS \\
Week & 2.98 & 15 & 0.2 & 0.2 & NS \\
GDM & & & & & \\
Treatment & 277.5 & 2 & 138.7 & 0.02 & $*$ \\
Week & 2392.5 & 15 & 159.5 & 0.001 & $* * *$ \\
TN & & & & & \\
Treatment & 22.8 & 2 & 11.5 & 0.001 & $* * *$ \\
Week & 67.5 & 15 & 4.5 & 0.001 & $* * *$ \\
CP & & & & & $* * *$ \\
Treatment & 175.5 & 2 & 87.8 & 0.001 & $* *$ \\
Week & 551.6 & 15 & 36.8 & 0.001 & $*$ \\
\hline
\end{tabular}


When performing the multi-factorial ANOVA of $\mathrm{pH}$, GDM, TN, it was shown that there are highly significant differences between the frequencies of application of LEBAME and the weeks studied for all variables, with the exception of $\mathrm{pH}$.

Figure 4 represents the behavior of the $\mathrm{pH}$ and total nitrogen, analyzed in terms of the treatment factor.

Although there is no statistically significant difference in $\mathrm{pH}$ levels, the one observed in treatment 2, is adjusted to the range referred by, Uribe et al. ${ }^{13}$ that recognizes that the $\mathrm{pH}$ between 7.5-8.5 is favorable for microbial activity and that above this it can be critical, due to the

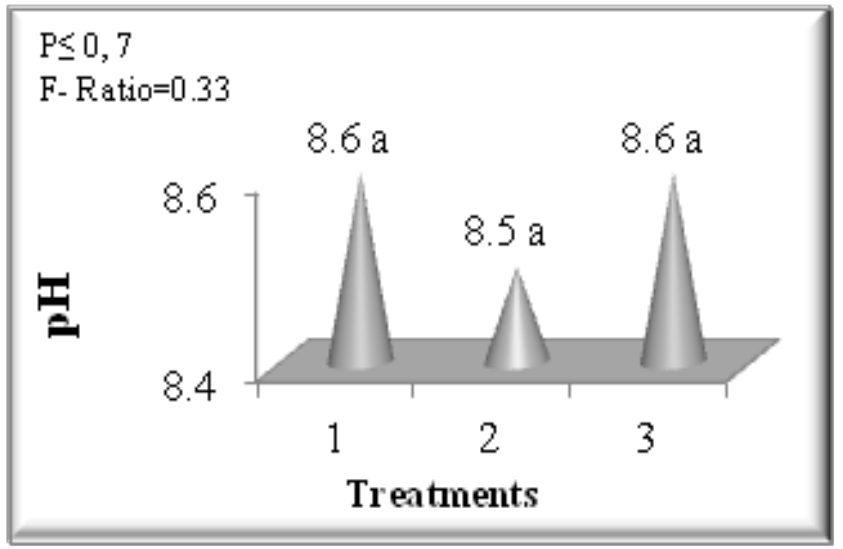

emission of ammonia gases. The addition of quick lime to the pits, due to its alkaline state, favors the release of ammonia into the medium, contrary to the expected effect with the application of LEBAME.

The total nitrogen does not differ significantly between the treatments where LEBAME was applied with different application frequencies, but it differs from the control treatment $(\mathrm{P} \leq 0.001)$. Noting that the higher nitrogen values were observed in the treatment where LEBAME was applied 3 times a week.

The behavior of the $\mathrm{pH}$ with respect to the time factor is shown below in Figure 5.

Figure 4 Behavior of $\mathrm{pH}$ and Total nitrogen by treatments.

$*$ Values with uncommon letters differ from each other by LSD top $\leq 0.05$.

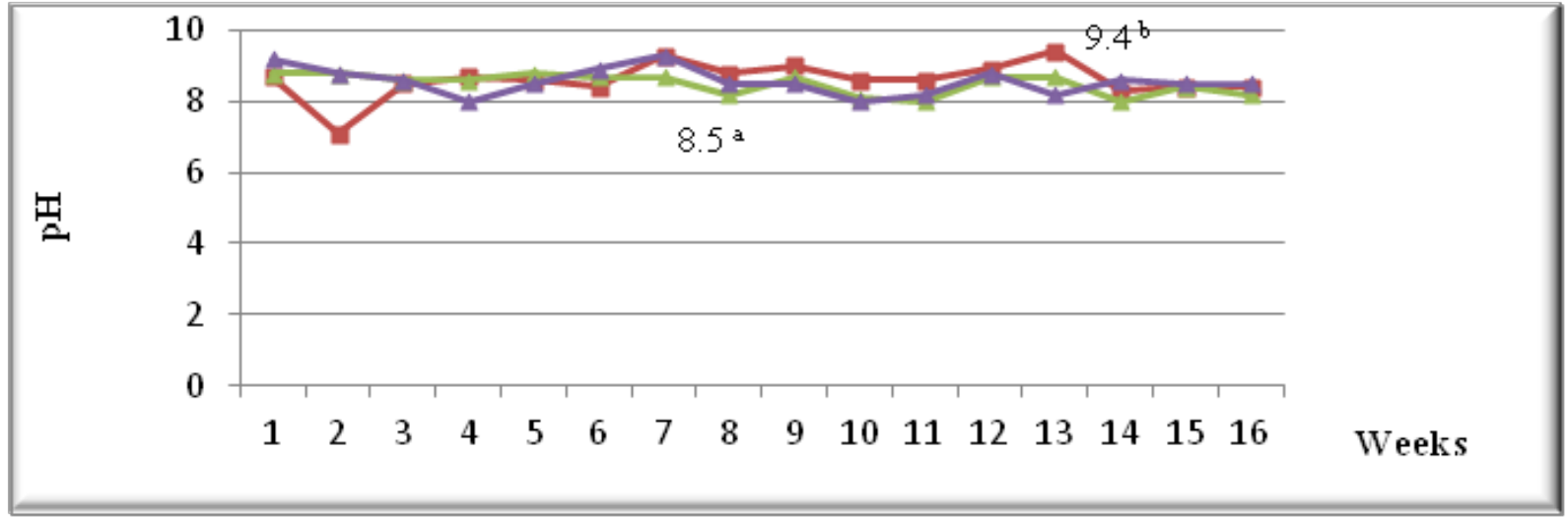

Figure $\mathbf{5} \mathrm{pH}$ behaviors over time.

$*$ Values with uncommon letters differ from each other by LSD top $\leq 0.05$

The behavior of the $\mathrm{pH}$ does not show a significant difference between the weeks studied for the treatments. The graph shows that the highest levels correspond to the control treatment (9.4), demonstrating the favorable action of LEBAME, which achieves $\mathrm{pH}$ stabilization below 8.5 in treatments 2 and 3 from week 8 , which for the control treatment was in week 14 . This coincides with what was raised by Miyashiro and Meggs, ${ }^{17}$ when referring to the action of efficient microorganisms in the acceleration of the stabilization of digestible materials and manure, by providing a greater microbial activity.

\section{In the swine industry}

El LEBAME inoculated in the digester system functioned as a catalyst for the decomposition of excreta, decreasing the time for the production of methane gas, in addition to this is more purified. The

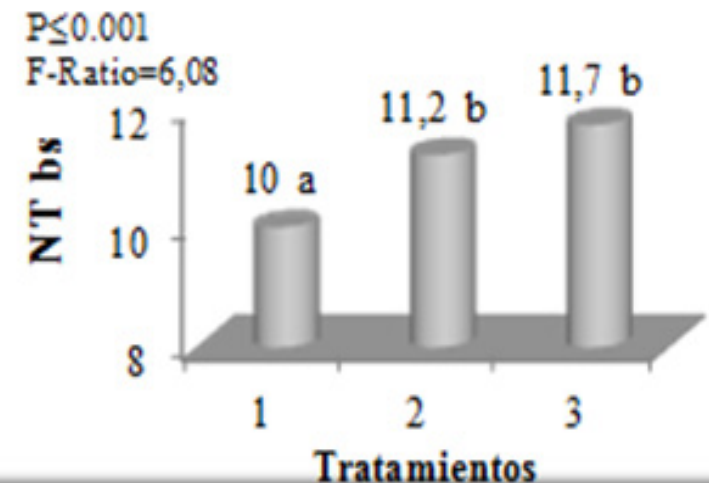

\section{$\mathrm{P} \leq 0.001$}

F-Ratio $=6,08$

Iratamientos judges of the test panel agree on the criterion that as the concentration of LEBAME increases, the bad smell of the system is reduced.

Furthermore it was observed that with the inoculation of LEBAME, the digestion of organic matter is accelerated, and consequently it reduces the demand for biological oxygen (BOD) and efficiently reduces harmful gases such as ammonia, hydrogen sulfide, and mercaptan, coinciding with that reported by Rojas, ${ }^{18}$ and Naranjo. ${ }^{19-23}$

\section{Conclusion}

1. The use of LEBAME, improves the environmental quality of poultry and swine facilities, reducing bad odors and populations of insect pests, meaning an economic, social and environmental benefit. 
2. The inoculation of LEBAME in bio-digesters accelerates the digestion of organic matter and, consequently, reduces the demand for biological oxygen (BOD) and harmful gases, such as ammonia, hydrogen sulfide and mercaptan.

\section{Acknowledgments}

None.

\section{Conflicts of interest}

The authors declare that there is no conflict of interest regarding the publication of this article.

\section{References}

1. Andrial P. Management of poultry, Brochure for the study of the subject of Special Zootechnics. UNAH; 2002.

2. Costa A, Urgel O. The new challenge of slurry. EDIPOR. 2000. 24 p.

3. Smith KA, Brewer AJ, Crabb J, et al. survey of the production and use of animal manures in England and Wales. Soil Use and Management. 2001;17:48.

4. Ogunwande GA, Osunade JA, Ogunjimi LAO. Effects of carbon to nitrogen ratio and turning frecuency on composting of chicken litter in turned-windrow piles. Agricultural. 2008 9:7495-7503.

5. Bitzer CC, Sims JT. Estimating the availability of nitrogen in poultry manure through laboratory and field studies. J Environ Qual. 1998;17(1):47-54.

6. Rizzo P, Della Torre V, Riera N, et al. Co-composting of poultry manure with other wastes from pampean region. J Mater Cycles Waste Manage. 2013.

7. Kelleher BP, Leahy JJ, Henthan AM, et al. Advances in poultry litter disposal technology- a review. Bioresource technology. 2002;83:27-36.

8. Higa T. Studies on purification and recycling of animal waste using effective microorganism (EM). 1995. 7 p.

9. Higa T. Beneficial and effective microorganisms for an agriculture and sustainable environment. 1993.

10. Technical Instructions. 2003.

11. Ferrer J, Paez G, Chirinos M. Aerobic bioprocess of the coffee pulp. Technical Journal of Engineering of the University of Zulia. 1994;17:6774
12. Moore PA, Huff WE, Daniel TC, et al. Effect of aluminum sulfate on ammonia fluxes from poultry litter in commercial broiler houses. proceedings of fifth international symposium on livestock environment, transactions of the ASAE 2. 1997:883-891.

13. Uribe JF, Estrada M, Córdoba S, et al. Evaluation of effective microorganisms (EM) in production of organic fertilizer from the manure of cage birds. Rev Col Cienc Pec. 2001;14:2.

14. Alvarez Perdomo GR, Pilco Llamba LN, Valverde Moreira HE, et al. The use of efficient microorganisms in the diet for broilers. REDVET. 2017.

15. Rostagno HS, Dionizio M, Paez LE, et al. Impact of broiler nutrition on the environment. Proceedings XVIII Latin American Poultry Congress; 2003. $431 \mathrm{p}$.

16. Brown M. Modes of action of probiotics: recent developments. Animal and Veterinary Advances. 2011;10(4):1895-1900.

17. Miyashiro G, Meggs JC. Measurement of the effect of the application of efficient microorganisms (EM) in the generation of methane gas $\left(\mathrm{CH}_{4}\right)$ in scale bio-digester systems. 2007.

18. Rojas Parraga, Hugo Ricardo. Study of the effect of the application of effective microorganisms (EM) in a process of anaerobic bio digestion Universidad Nacional Agrarian La Molina. Science Faculty, Academic Department of Environmental Engineering, Physics and Meteorology. 2014.

19. Naranjo EI. Application of microorganisms to accelerate the transformation of organic waste into compost. Research as a requirement to choose the title of agronomist. Ambato, Ecuador: Technical University of Ambato; 2013.

20. Higa T. Beneficial and Effective Microorganism for a Sustainable Agriculture and Environment International Nature Farming Rese arch Center Atami, Japan. 1994. 16 p.

21. Applications and Uses of $E M=1 \circledR$ in Poultry: Official Portal of EM ${ }^{M T}$ Technology in Latin America. 2018.

22. EM $^{\circledR}$-Effective Microorganisms. ECO technologies. 2018.

23. Tobia C, Vargas E. Evaluation of the excreta of broilers (poultry litter) in animal feed. Availability and chemical composition. Costa Rican Agronomy. 2000;24(1):47-53. 